\title{
"Questão Social", intervenção profissional e projeto ético-político: três perspectivas para pensar as formas de consolidação de uma teoria e prática crítica para o Serviço Social Colombiano ${ }^{1}$
}

\author{
"Social Issue", professional intervention and ethical-political project: Three perspectives to \\ think about the forms of consolidation of a theory and critical practice for the Colombian \\ Social Service
Maria Luiza Adoryan Machado* Suelen Ferreira Moraes** Maira Meira Pinto*** Marisol Valencia Orrego****

\begin{abstract}
Resumo: Este artigo surge como resultado de uma investigação sistemática que ocorreu entre os anos de 2009 e 2014, sobre os fundamentos teórico-metodológicos, ético-políticos e instrumental operativos do Serviço Social através da perspectiva histórico-crítica consolidada na produção bibliográfica brasileira. A exposição do artigo se divide em duas partes: a primeira, na qual se descreve a questão social e a intervenção profissional sobre as expressividades da questão social. E, a segunda, em que se ingressa no projeto ético-político profissional, descrevendo os fundamentos nos quais se sustentam os projetos de sociedade e profissional. Esta abordagem leva a pensar na alternativa de um projeto profissional progressista no marco da dimensão ético-política, que desde a perspectiva histórico-crítica vem fornecendo ferramentas para articular três aspectos que estão relacionados "questão social", intervenção profissional e projeto ético-político - para pensá-los relacionados com uma teoria e prática crítica na realidade social, em que este se envolve nas contradições impostas desde o capitalismo.
\end{abstract}

Palavras-chave: Intervenção profissional. Questão social. Projeto ético-político. Perspectiva histórico-crítica.

Abstract: This article emerges because of a systematic investigation, from 2009 to 2014, of the theoretical-methodological, ethical-political, and instrumental foundations of the Social Service through the historical perspective-consolidated criticism in the Brazilian bibliographic production. The article is divided into two parts: the first, in which the social issue and the professional intervention on the expressivities of the social issue are described. And the second, in which it is entered in the professional ethical-political project, describing the foundations in which the projects of society and professional are supported. This approach leads to thinking about the alternative of a progressive professional project in the framework of the ethical-political dimension, which from the Historicalcritical perspective has been providing tools to articulate three aspects that are related - "social issue", professional intervention and ethical-political project - to think of them related to a theory and critical practice in the social reality, in which it is involved in the contradictions imposed since capitalism.

Keywords: Professional intervention. Social issue. Ethical-political project. Historical-critical perspective.

\footnotetext{
${ }^{1}$ Este texto é uma tradução do artigo original: ORREGO, Marisol Valencia. (2014). "Cuestión social”, intervención profesional y proyecto ético-político. Triada para pensar las formas de consolidación de una teoría y práctica crítica para el trabajo social colombiano.

* Acadêmica do curso de graduação em Psicologia na Universidade de Santa Cruz do Sul (UNISC).

*** Estudante de graduação em Serviço Social na Universidade de Santa Cruz do Sul (UNISC).

*** Doutora em Educação pela Pontifícia Universidade Católica do Rio Grande do Sul (PUC-RS).

**** Doutora em Serviço Social pela Universidade Federal do Rio de Janeiro-UFRJ.
} 


\section{Introdução}

Reconhecer a pluralidade de perspectivas do Serviço Social possibilita conhecer as diferentes visões que existem na profissão. Neste caso, a perspectiva histórico-crítica permite visualizar com totalidade sobre a "questão social" enquanto um processo transversal na história da sociedade burguesa no modo de produção capitalista, representando as características das etapas do capitalismo e apresentando o cenário de intervenção do(a) Trabalhador(a) Social.

A partir de uma passagem pelo desenvolvimento histórico de fundamentação teórica da perspectiva histórico-crítica do Serviço Social produzido no Brasil entre 1997 até 2007, é possível identificar análises da realidade social e profissional que tencionaram e tencionam a prática profissional frente ao contexto mundial e nacional. Esta abordagem permite reconhecer a "questão social" como um assunto central, tanto na profissão como nas determinações que geram a criação de políticas públicas para combater as desigualdades, deixando claro de que quando se fala de "questão social" se devem pensar os diferentes campos profissionais e as formas de pensar a profissão e de como se relaciona e reproduz o modo de produção capitalista, assim como as dimensões que orientam o projeto éticopolítico.

Este artigo surge como resultado de uma investigação sistemática que ocorreu entre os anos de 2009 e 2014, proveniente de uma dissertação, sobre os fundamentos teóricometodológicos, ético-políticos e instrumental operativos do Serviço Social através da perspectiva histórico-crítica consolidada na produção bibliográfica brasileira.

\section{O desenvolvimento da "questão social"}

As abordagens investigadas a partir da perspectiva histórico-crítica sobre a "questão social" estão relacionadas: ao sistema econômico capitalista, ao Estado (NETTO, 1997), à sociedade civil, ao terceiro setor e ao novo tratamento dado a "questão social" no contexto de "reestruturação do capital" (MONTAÑO, 2005, p. 238), as políticas sociais e, portanto, a intervenção desenvolvida pela/o profissional do Serviço Social.

Para compreender em essência no que se refere o termo "questão social", tem sido 
desenvolvida por alguns estudiosos do Brasil a descrição teórica articulada a uma análise histórica que a determina na sociedade atual e na profissão como “(...) a base de sua fundação como especialização do trabalho" (IAMAMOTO, 2003, p. 41).

O termo "questão social", como descreve José Paulo Netto, em "Cinco notas a propósito da questão social" (2003), não é um conceito unívoco ${ }^{2}$, porque em seu desenvolvimento histórico tem sido utilizado pelas diferentes tendências da racionalidade imperante na sociedade capitalista.

A conceituação do termo "questão social" passa por diferentes momentos. Primeiro, se relaciona com a concepção da "pauperização" ${ }^{3}$, assim como inicia uma mudança de sentido em sua denominação e compreensão quando se transforma o tratamento dado em função dos movimentos históricos produzidos na Europa no século XIX. Segundo Netto (2003, p. 59), "foi a partir da perspectiva efetiva de uma subversão da ordem burguesa que o pauperismo se designou como "questão social".

Esse movimento histórico resultante da luta de classes sociais não enquadra a "questão social" como um assunto exclusivo e nem como uma categoria resultante do processo revolucionário, devido ao que é adotado ao mesmo tempo pelo "vocabulário" do pensamento conservador abordado pelos laicos, que consideram que as suas consequências “(...) são vistas como o desdobramento na sociedade moderna ${ }^{4}$ (leia-se: burguesa), de características não elimináveis de toda e qualquer ordem social, que podem ser objeto de uma intervenção política limitada" (NETTO, 2005, p. 60), e por conservadores confessionais, que “(...) apelam a medidas sócio-políticas para diminuir as suas consequências (...) e (...) se insiste em que somente sua exacerbação contrária à vontade divina (aqui é emblemática a lição de León XIII de 1891)" (NETTO, 2003, p. 60).

2 Que responde a várias interpretações.

${ }^{3}$ De acordo com Netto (apud BORGIANNI; MONTAÑO, 2003, p. 58), pela primeira vez registrada na história, a pobreza crescia em razão direta com o aumento da capacidade social de produzir riquezas. Quanto mais a sociedade se revelava capaz de produzir progressivamente mais bens e serviços, assim como aumentava o contingente de seus membros, que não tinham acesso efetivo a tais bens e serviços, viam-se despossuídos das condições materiais da vida que tinham anteriormente.

4 “Em nítido contraste com essa oposição óbvia, o uso problemático do termo 'moderno' se caracteriza pela tendência de esquecer a dimensão sócio-histórica, a serviço dos interesses dominantes da ordem estabelecida. Fiéis a esse espírito, as definições de 'modernidade' exigidas são construídas de tal maneira que as especificidades socioeconômicas são ofuscadas ou deixadas em segundo plano para que a formação histórica descrita como uma 'sociedade moderna' nos vários discursos ideológicos sobre a 'modernidade' possa adquirir um caráter paradoxalmente atemporal em direção ao futuro por causa de sua contraposição, acriticamente exagerada, ao passado mais ou menos distante" (MÉSZÁROS, 2004, p. 70). 
"Questão Social", intervenção profissional e projeto ético-político: três perspectivas para pensar as formas de...

Ambas as posturas conservadoras, a laica e a confessional, apontam a fragmentação, segmentação e naturalização da "questão social" através da moralização do homem e da sociedade. De acordo com Netto (2003, p. 60), em ambos os casos, o enfrentamento de suas manifestações deve ser função de um programa de reformas que, inicialmente, preserve a propriedade privada dos meios de produção.

Em meio aos diferentes usos do termo em questão, Netto (2003) afirma que as particularidades resultantes de 1848 produzem no ideário político uma ideologia com rupturas sem salvação, que são expressas mais claramente em sua obra:

Essa (a explosão de 1848) ${ }^{5}$ feriu sustentavelmente as bases da cultura política que existia desde o movimento dos trabalhadores: explicitando o caráter antagônico dos interesses sociais de classes fundamentais, 1848 implicou na dissolução da ideologia formulada pela utopia (...) um dos resultados de 1848 foi a passagem do proletariado, em nível histórico universal, da condição de "classe em si" para "classe para si". Os trabalhadores, em seu processo de luta, acenderam a consciência política de que a "questão social" está necessariamente vinculada à sociedade burguesa: somente a supressão desta conduz a supressão daquela (NETTO, 2003, p. $61)$.

O reconhecimento do uso e naturalização que pretende ser levado a fundo no pensamento conservador faz com que o pensamento revolucionário se distingue a questão social, as quais representam o reconhecimento do chamado "traço mistificador" (NETTO, 2003, p. 61).

Continuando do ponto que marca a "questão social" como tema relevante para ser interiorizado à racionalidade crítica, aborda-se Marx, que desenvolve sua produção teórica, como aponta Netto (2003, p. 62):

Somente com o conhecimento rigoroso do "processo de produção do capital" Marx pôde apresentar com precisão a dinâmica da "questão social", consistente em uma complexidade problemática muito ampla, irredutível à sua manifestação imediata como pauperismo.

Segundo Netto (2003, p. 62-63), a relevância outorgada no transcorrer das suas obras para a descrição da posição da classe trabalhadora na luta de classes e o reconhecimento do desenvolvimento do capitalismo e as formas de acumulação do capital estabelecem que a "questão social" está basicamente determinada pelo traço próprio e peculiar da relação

${ }^{5}$ Comentário externo à citação. 
capital-trabalho.

Mediante este último postulado, encontra-se em Netto (1997) outras abordagens que apontam a relação existente entre "questão social", Estado e capitalismo dos monopólios, especificando a necessidade de expressar a pluralidade de compreensões que em geral desde o universal e o particular apontam para uma análise a partir da visão marxista que revela o contexto capitalista sobre a "questão social":

(...) nas palavras de um profissional do Serviço Social: "a questão social nada mais é que as expressividades do processo de formação e desenvolvimento da classe trabalhadora e do seu ingresso no cenário político da sociedade, exigindo o reconhecimento como classe por parte do empresariado e do Estado. É a manifestação, no cotidiano da vida social, da contradição entre o proletariado e a burguesia" (NETTO, 1997, p. 5).

Mediando essa relação entre as classes sociais é evidenciado o papel do Estado no capitalismo monopolista e a administração da "questão social", ao que indica a trajetória histórica que atravessa a categoria em questão e a sua relevância ou naturalização.

Desta forma, o papel do Estado burguês de intervir mediante as políticas sociais caracterizada por tendência conservadora e, portanto, fragmentária da realidade social, se dá

(...) a partir da concretização das possibilidades econômicas-sociais e políticas segregadas na ordem monopolista (concretização variável do jogo de forças políticas) em que a "questão social" se coloca como alvo das políticas sociais (NETTO, 1997, p. 19).

Em Netto (1997), a intenção de aumentar o panorama sócio-histórico, a partir de onde o Serviço Social se insere (capitalismo monopolista) através da divisão sociotécnica do trabalho, ressaltou a grande contribuição na história dos acontecimentos que posicionavam a "questão social" no marco da sociedade capitalista.

Para entender as determinações deste tema na profissão, a partir de uma visão histórico-crítica, deve ser levado em conta que esta perspectiva entra em conflito com as análises tradicionais da gênese profissional, que entende e naturaliza o Serviço Social enquanto profissão criada para administrar, gerenciar e dar continuidade à assistência, caridade, beneficência e filantropia, das quais eram função de organizações religiosas ou laicas conservadoras.

Essa visão histórica da questão social entendida como a contradição que as classes 
"Questão Social", intervenção profissional e projeto ético-político: três perspectivas para pensar as formas de...

sociais estabelecem na sociedade burguesa e que se sustenta no modo de produção capitalista, coloca a profissão como parte desse conflito de classes, colocando o(a) Trabalhador(a) Social como um(a) profissional que realiza a mediação das relações entre o Estado e outras instituições públicas e privadas para conter as desigualdades derivadas da focalização de políticas universais que se sustentam em direitos universais.

Assim, as análises produzidas na perspectiva histórico-crítica para o Serviço Social vinculam a "questão social" com a intervenção profissional, referindo-se à atuação de um agente que não é neutro, nem representa um voluntário com vocação confessional que busca o bem da humanidade, mas sim, um agente de uma classe social (leia-se proletariado ou classe trabalhadora), que vende a sua força de trabalho para conseguir os meios de sobrevivência e que, portanto, deve politizar a sua atuação, entendendo que as suas ações mediam as contradições do capitalismo e que o(a) próprio(a) Trabalhador(a) Social faz parte desta população majoritariamente excluída da qual atende.

\section{A intervenção profissional sobre a "questão social"}

A política social é o cenário próprio onde intervém o(a) Trabalhador(a) Social e onde se enfrentam as expressividades da "questão social", mediante o qual o Serviço Social demarca "a base de sua fundação" (IAMAMOTO, 2003, p. 41).

Essa premissa vinculante onde estabelecem relações entre o Estado, a "questão social" e a(s) política(s) social(is), permitem pensar e analisar a intervenção profissional a partir das concepções teóricas que se produzem sobre o capitalismo, reconhecendo as restrições na margem de atuação profissional no contexto socioeconômico e político atual.

É, portanto, que o espaço, onde o Serviço Social transitará pelo capitalismo monopolista como eixo da sua fundação e operatividade frente ao Estado, vem experimentando mudanças que vão com a dinâmica do movimento de relações sociais de produção que se estabelecem no período de desenvolvimento econômico e social que considera-se em crise $^{6}$ na atualidade mundial.

Sobre as etapas do capitalismo existem tendências teóricas (inclusive no Marxismo) que argumentam que o modo de produção capitalista (MPC) encontra-se no período de

\footnotetext{
${ }^{6}$ A crise do capital é um tema abordado por Mészaros em seu livro titulado "Crisis Estructural del Capital".
} 
"globalização", o qual outros teóricos referem-se como "mundialização do capital", com diferenças conceituais, mas ambos os autores concordam que o capital na atualidade passou da dimensão redistributiva para acumulativa ${ }^{7}$.

Neste cenário, as dinâmicas têm entrado em uma transformação radical, já que o Estado, que cumpria funções de controle frente a redistribuição do capital, está minimizando a sua ação, e o seu papel principal como regulador da economia vem sendo diminuído.

No capitalismo global, os projetos do bem-estar social do primeiro mundo, os desenvolvimentistas do terceiro mundo e o projeto de regulação da economia do segundo mundo, entram em colapso; levando com que o capital, a mão de obra ou a força de trabalho, entrem em tensão e antagonismo, confrontando-se a partir de certas condições em que se estabelecem novos parâmetros. É assim que se desregula a mão de obra, mediante a flexibilização e as reformas laborais que atentam contra as conquistas do sindicalismo mundial, o que leva a que a regulação deste tema já não se encontre nas mãos do Estado, pois passa para as mãos de outros setores da economia: o terceiro setor.

O sistema de acumulação capitalista avança através de extensas ondas de privatização e o que anteriormente foram consideradas como pautas para a luta social. Os direitos humanos universais (saúde, educação etc.) e os bens universais (água e seus mínimos fundamentais) passam a ser serviços comerciáveis, vendáveis e não mais defendidos e tutelados. Estas concessões do Estado para instituições privadas entram para fortalecer o capital da "elite", ou classe capitalista transnacional, desaparecendo com a abertura econômica e a globalização na qual a classe burguesa nacional é substituída pelo cooperativismo e por uma nova classe transnacional.

\footnotetext{
7 É decisivo ressaltar que, para Mészáros, capital e capitalismo são fenômenos distintos. O sistema de capital, segundo o autor, antecede o capitalismo e tem vigência nas sociedades pós-capitalistas. O capitalismo é uma forma possível de realização do capital, e uma de suas variantes históricas, presente na fase caracterizada pela generalização da subseção do trabalho ao capital que Marx denominava como "capitalismo pleno". Assim como existia capital antes da generalização do capitalismo (tais como capital mercantil, capital usuário, entre outros), as formas recentes de metabolismo sócio metabólico permitem constatar a continuidade do capital incluso depois do capitalismo, através da constituição daquilo que Mészáros denomina como "sistema de capital póscapitalista", tendo como exemplos a URSS e demais países do oeste europeu. Esses países pós-capitalistas não conseguiram romper com o sistema de metabolismo social do capital e a identificação conceitual entre capital e capitalismo, sendo que, segundo o autor, todas as experiências revolucionárias vividas neste século mostravam-se incapazes de superar o sistema de metabolismo social do capital (a complexidade caracterizada pela divisão hierárquica do trabalho, que suborna suas funções fundamentais para o capital). Para uma melhor compreensão da experiência soviética, ler o capítulo XVII, itens 2, 3, e 4 de "Más allá del Capital". Sobre as mais importantes diferenças entre o capitalismo e o sistema soviético, ler a síntese no livro "Pinas 630/1" (MÉSZÁROS, 2009).
} 
"Questão Social", intervenção profissional e projeto ético-político: três perspectivas para pensar as formas de...

Atualmente, enfrentamos a mesma realidade social com fatores que incidem nas mudanças das políticas sociais e econômicas que determinadas por projetos transnacionais incidem nas condições sociais ao interior dos países. O caso da perda de bancos regionais, a chegada de comércios internacionais que representam e detêm os produtos e serviços comerciais, sendo as "grandes cadeias do mercado", vão extraindo o capital da circulação nacional e o põe em circulação transnacional. Assim, aparecem formas de extração do capital da mão da oferta de turismo enquanto serviço transnacional característico em países que possuem esta dinâmica global, a agroindústria em posse de corporações de manipulação genética de sementes, a exportação da mão de obra (máquinas em alto mar) que relacionase com a expropriação dos direitos civis e sociais adquiridos nas lutas revolucionárias.

Estas condições que precarizam a economia interna, que aumentam a terceirização e substituem os contratos de trabalho por contratos de prestação de serviços, colocam a classe trabalhadora em uma encruzilhada onde a perda das condições mínimas de direitos alcançados são arrebatados pelas classes dirigentes que vendem as políticas econômicas e beneficiam as políticas de globalização.

As consequências se produzem na sociedade, e este impacto traz consigo a fragmentação e focalização das políticas de educação, saúde e moradia, com distribuição desigual de renda no capitalismo, que acaba por aumentar a pobreza, o desemprego e a perda de condições dignas de viver, assim como o acesso a bens e serviços que restam para gerir na camada majoritária da população, que como resultado das condições laborais, se veem obrigadas a vender a sua força de trabalho conforme a precariedade e competências desiguais impostas pelo sistema.

Outro aspecto somado a esse panorama sombrio do capitalismo é o uso do regime de terror para amedrontar a sociedade e a população ao estabelecer mecanismos de mobilização social que determinem mudanças sustentáveis na realidade social; é o caso específico dos deslocamentos forçados, as migrações, a perseguição ideológica, a criminalização do protesto social pacífico e o direito de rebeldia dos povos frente a injustiça de seus governantes e governos.

Os mecanismos de terror em questão geram condições especiais ao mercado transnacional, permitindo o ingresso de grandes capitais para a exploração de recursos naturais, o acesso à propriedade através da posse pela força e/ou amedrontamento psicológico, aumentando a passividade nas pessoas por medo em defender os seus direitos e 
intensificando a precarização do valor da força de trabalho, levando a população a viver em cinturões de miséria nas cidades em níveis de extrema pobreza.

Estas expressividades da "questão social" 8 na atualidade são as que determinam as condições de trabalho do Serviço Social. Os profissionais interferem e operam políticas de distribuição de renda moldadas pelo Banco Mundial e o Fundo Monetário Internacional em suas políticas de combate à pobreza, que cada país adota para baixar os níveis de desigualdade.

Na Colômbia, a Agência Nacional para a Superação da Pobreza Extrema (ANSPE), e os múltiplos programas que se desprendem dela para dar atenção às populações deslocadas, marginalizadas, que vivem em extrema pobreza, são um claro exemplo de uma política social onde há o enfoque da intervenção profissional das ciências sociais.

Porém, por este cenário ser concorrido por muitas áreas, um grande desafio que os profissionais enfrentam são os processos de exclusão laboral que, como classe trabalhadora, têm competido no campo com os seus colegas de profissão, assim também, a Antropólogos, a Sociólogos e um ou outro Técnico ou Tecnólogo que opera as políticas sociais.

Nesta lógica, se planeja uma dinâmica de intervenção profissional determinada pelas normas do mercado em que se inserem as condições que são estabelecidas pelo terceiro setor, as organizações, o Estado e as instituições, onde o Serviço Social realiza a execução e, às vezes, o estudo, o desenho e a avaliação de políticas sociais privadas ou públicas, implementadas pelos diferentes órgãos que as disputam, convertendo-se em outro mercado de competência para a profissão.

Configura-se, então, a inserção dos profissionais no campo da fragmentação dos "problemas sociais" que ocultam o fundo dos antagonismos da sociedade mundial e que continua com o papel reprodutor das relações sociais no sistema capitalista que parece que estamos destinados a cumprir sem questionar.

Mediante este cenário complexo que apresenta o modo de produção capitalista é necessário que o profissional tenha as ferramentas de análise histórico-crítica para compreender a realidade social a partir de uma perspectiva de totalidade, permitindo

8 Ao referir aqui com as expressões da "questão social" coincide com a postura da perspectiva histórico-crítica que apresenta que não há uma nova questão social, mas sim diferentes expressões dela. Ler a proposta de Netto em Borgianni e Montaño (2003, p. 55-69), na nota 4 aparece uma alusão do tema específico da denominação de “Nova questão social” (BORGIANNI; MONTAÑO, 2003, p. 66). 
"Questão Social", intervenção profissional e projeto ético-político: três perspectivas para pensar as formas de...

estabelecer estratégias de intervenção baseadas em um projeto de sociedade revolucionária, progressista, que permite remover o manto da naturalidade que se coloca com uma visão ahistórica, que naturaliza as contradições instaladas na racionalidade da sociedade burguesa.

\section{Projeto ético-político profissional}

O panorama profissional que se visualiza mediante a perspectiva histórico-crítica a partir dos principais intelectuais que aprofundam-se nos fundamentos teórico-metodológicos, ético-político e técnico instrumental, foi permitido sustentar as bases das dimensões da prática profissional reconhecendo em seus fundamentos as bases para pensar a "ontologia do ser social".

Além de pretender-se abordar separadamente cada uma das dimensões mencionadas, busca-se relacionar coerentemente as categorias que aportam elementos na relação com a intervenção profissional, identificando os aspectos que subjazem os debates sobre a construção do processo que orienta o projeto ético-político.

Em relação ao projeto e intervenção profissional, o que se tem produzido no marco da perspectiva histórico-crítica é o reconhecimento de avanços e desafios resultantes das tensões e lutas, divergências e contradições que são gerados ao interior do projeto coletivo, que transita no caminho dos interesses e finalidades orientadas por um marco ideal da profissão, uma normatividade jurídica e uns valores que a legitimam, a função social, os objetivos, os conhecimentos teóricos, o saber interventivo e as práticas (NETTO, 2003, p. 274). Este aponta o Serviço Social como uma profissão inserida na divisão sociotécnica do trabalho e que também implica intenções individuais e coletivas que apontam à articulação de um projeto de sociedade.

Sendo assim, a abordagem das características do projeto de sociedade e o projeto profissional são fundamentais para compreender o desenvolvimento profissional em relação às contribuições para a intervenção desde a perspectiva histórico-crítica, enquanto se entendem as ações resultadas de um processo histórico do coletivo profissional, articulando mediante a correlação de forças sociais.

Neste panorama, conjugam-se as dimensões ética e política para a construção do projeto profissional a partir da racionalidade crítica, deixando claras as contribuições que o Serviço Social brasileiro faz tanto à história profissional com a forma de abordar a intervenção profissional. 


\title{
Projeto de sociedade e projeto profissional
}

A construção de relações tem a sua essência na composição social. Com isso, há sentido em compreender o que é um projeto de sociedade, já que não podemos segregar as ações individuais da influência e correlação que existe com as relações que se estabelecem em níveis mais amplos.

Neste sentido, um projeto de sociedade é colocado e moldado em condições particulares que o configuram como tal, e é assim que cada etapa do desenvolvimento da humanidade tem se instalado em um projeto específico, sendo fundamental para isso a produção e reprodução das relações sociais que configuram os modos de produção em que os sujeitos estabelecem as formas de relacionarem-se entre eles e com as instituições que se criam para a regulação da vida em sociedade.

Os projetos de sociedade, por sua vez, são mobilizados por um conjunto de sujeitos que convergem os seus ideais de sociedade. Sobre isso, José Paulo Netto (2003) afirma que existem projetos individuais, coletivos e societários, e cada um estabelece uma relação e influência sobre os demais, já que não se podem pensar desarticulados, embora que em certos casos transparece entre eles relações antagônicas que os distanciam.

À luz das dimensões ética e política, afirma-se que

\begin{abstract}
os projetos societários são projetos coletivos; mas o seu traço peculiar reside no fato de se tornarem projetos insignificantes como propostas para o conjunto da sociedade (...) aqueles que apresentam uma imagem de sociedade a ser construída, que regulamentam determinados valores para justificá-la e que privilegiam certos meios (materiais e culturais) para concretizá-las (NETTO, 2003, p. 273).
\end{abstract}

Neste mesmo sentido, Carlos Montaño (2006) expressa que no desenvolvimento da sociedade se ressaltam três projetos que são apresentados em conflito por suas intenções e finalidades contraditórias. Eles são: o projeto neoliberal, o projeto reformista e o projeto revolucionário.

Compreende-se, então, que estes três tipos de projetos têm tido pontos de convergência temporal e espacialmente na história da humanidade, e frente a eles existem lógicas econômicas, políticas e sociais que determinam sua visibilidade ${ }^{9}$ na realidade social, a

\footnotetext{
${ }^{9}$ É necessário ressaltar que surge uma visibilização do âmbito econômico, contrário ao que se entende por determinismo econômico, já que se compreende que a relação entre os âmbitos é maior ou menor segundo o
} 
"Questão Social”, intervenção profissional e projeto ético-político: três perspectivas para pensar as formas de...

ordem econômica na qual se instalam, gerando uma influência sobre os demais. Frente a isso, os dois primeiros projetos societários apontam em maior ou menor proporção a promover o desenvolvimento do capitalismo.

No projeto neoliberal, prevalece a interferência do mercado através do capital como regulador das relações sociais. No projeto reformista, é apaziguada a determinação do mercado mediante o controle do Estado, mas prevalece entre elas a relação capitalista sob as relações sociais, preponderando a propriedade privada, subsumindo a isso as políticas sociais e de caráter recipiente da "questão social"10. E por último, se encontra o projeto revolucionário que é "fundamentalmente de inspiração Marxista, que busca, gradual e abruptamente, a substituição da ordem capitalista por uma sociedade sem classes sociais, sem exploração, regida pelo trabalho emancipado" (MONTAÑO, 2006, p. 144). Nesse projeto, a finalidade tanto dos projetos individuais, coletivos e societários apontam a liberdade e à emancipação humana.

A partir da descrição anterior, evidencia-se que o sentido dos primeiros projetos de sociedade apresentados, que incluem por seus móveis as demandas e requerimentos sociais pela visível extrapolação que representa distâncias exponenciais entre as classes sociais ${ }^{11}$ que não têm nenhuma intenção de avaliar-se e que, pelo contrário, a diminuição das polaridades aponta exclusivamente para evitar um confronto direto que desencadeia ações revolucionárias, ou no mínimo, focos de rebeldia ${ }^{12}$.

A hegemonia de um ou outro projeto de sociedade está relacionado, por sua vez, com os mecanismos de expansão que o divulgam e reproduzem; não entrando em detalhes, mas lembrando que as condições de existência no sistema capitalista operante obedece às

momento histórico que atravessa a humanidade.

${ }^{10}$ No capitalismo do séc. XX, os projetos de bem estar social de primeiro mundo, os desenvolvimentistas do terceiro mundo e o projeto de regulação da economia do segundo mundo, colapsam; levando com que o capital (a força do trabalho) ampliem seu antagonismo enfrentado por outros meios.

${ }^{11}$ Os novos dados da pobreza publicados pelo Banco Mundial revelam que a quantidade de habitantes de países em desenvolvimento, que vivam com menos de US\$ 1,25 por dia, diminui de 1.900 milhões (um a cada dois habitantes) em 1981, para 1.400 milhões (um a cada quatro habitantes) em 2005. Estes dados demonstram que, durante os últimos 25 anos, a pobreza tem afetado mais do que o previsto no mundo em desenvolvimento, mas também se tem alcançado avanços consideráveis - embora distintos, se comparado com as regiões a partir da redução da pobreza em geral (WORLD BANK, 2008). Disponível em: <http://web.worldbank.org/WBSITE/EXTERNAL/BANCOMUNDIAL/NEWSSPANISH/0,,contentMDK:21883686 menuPK:51191012 pagePK:34370 piPK:34424 theSitePK:1074568,00.html>. Acesso em: 26 jul. 2020.

${ }^{12} \mathrm{Em}$ relação a este aspecto, o Serviço Social e o Assistente Social como executor de políticas sociais cumprem um papel determinante, tanto na sua função de contenção social, que legitima como necessário, quanto funcional para o sistema capitalista. 
lógicas pré-estabelecidas pela sociedade burguesa, deixando relegado o papel das classes trabalhadoras e subalternas.

Nas palavras de Netto (2003, p. 274):

os projetos societários que atendem os interesses das classes trabalhadoras e subalternas sempre dispõem de condições menos favoráveis para enfrentar os projetos das classes possuidoras e politicamente dominantes.

Sustentado nesses postulados, se compreende que o projeto de sociedade se consolida mediante uma ideologia, um grupo de normas jurídicas e normas morais que vão criando costume e, posteriormente, lei para quem as utilizam e as reproduzem, mas que, de uma forma geral, são imperativas para toda a população, embora não recorram ao interesse geral como fonte de seus mandados. É por isso que é necessário compreender que, embora, existe um projeto de sociedade hegemônico na sociedade, nela, confluem outros projetos societários que disputam posição através dos antagonismos, por vezes radicais em relação a forma em que se estabelecem as relações sociais ou as formas de produção, ou ambas.

Neste traço configurador das relações que produzem os projetos societários, se inscrevem os projetos profissionais, que chega carregado de projetos individuais e que, por sua vez, confluem nos projetos coletivos, consolidando o projeto de sociedade a partir da necessidade de condições de reprodução adequadas e permitindo difundir a essência do projeto a nível prospectivo. É nisso que se encontra sentido às profissões, encontrando nelas o sentido de instrumentalidade. Guerra e Montaño (2003, p. 178) afirmam que

(...) estamos considerando instrumentalidade como as propriedades sociais das coisas, atribuídas pelos homens no processo de trabalho ao convertê-las em meios/instrumentos para a satisfação de necessidades e o alcance de seus objetivos e finalidades. Tal capacidade que foi atribuída pelos homens no seu processo de produção da vida material através da sua posição teológica (realização de suas intenções).

E ainda, que a instrumentalidade é

(...) algo além de uma simples remissão a uma propriedade que as coisas adquirem na relação do homem com a natureza em atividades humanas orientadas para a satisfação de necessidades no processo de trabalho, mas ainda de um trabalho "alienado" típico das sociedades capitalistas em que os meios se transformam em forças produtivas do capital e são utilizados apesar de seus valores e seus fins (GUERRA; MONTAÑO, 2007, p. 136). 
"Questão Social", intervenção profissional e projeto ético-político: três perspectivas para pensar as formas de...

Em relação ao projeto profissional, se imagina que existem em seu interior hegemonias nas quais se confluem certas concepções e nas quais se acordam as formas de práticas e formação da profissão. Porém, como todo sistema em movimento, no interior da profissão, também coexistem outros projetos que têm ideais diferentes baseados em outro tipo de projeto de sociedade, distinguindo-se em alguns aspectos (projeto reformista) ou em todos (projeto revolucionário), do projeto hegemônico, gerando uma contradição radical e antagônica, que apesar disso, compreende e reconhece em seu interior a existência da pluralidade ${ }^{13}$ como eixo de sua dinâmica.

No Serviço Social a experiência não é diferente. Nele confluem a hegemonia do projeto de sociedade com o projeto profissional, contando com certos aspectos característicos segundo o contexto específico ${ }^{14}$, contudo, nele existem perspectivas que diferem do projeto profissional hegemônico, ressaltando uma postura política que ora posiciona e ora mantém distância das formas estabelecidas.

No projeto profissional, a influência dos meios, implantados pelas classes sociais dominantes, têm como ponto central as demandas do mercado, o Estado, e as organizações que validam e regulam a profissão e sua organização no sistema sociopolítico e econômico; estas determinações se abalam mediante a aprovação ativa ou omissiva dos sindicatos e/ou profissionais (entidades organizativas da profissão) que o conformam.

No caso do Brasil, o conflito do sindicato profissional sobre os pressupostos éticos e políticos, abordando "mínimos comuns" que suportam o legado de emancipação humana como aspecto fundamental, leva a pensar ações onde o coletivo se incline para acompanhar fatos que promovam condições de existência que defendem para reduzir ou abolir as bases que sustentam o capitalismo; estes aspectos devem ser estudados mais profundamente, já que é a partir deles que se conjugam as dimensões teórico-metodológicas, ético-política e instrumental operativa, onde se funda e sustenta o projeto ético-político profissional. Neste caso, sabe-se que as entidades que estabelecem mínimos comuns para o trabalho e a

\footnotetext{
${ }^{13}$ Pluralidade entendida como a possibilidade em que se instalam outros projetos individuais e coletivos que apontam diferentes posições para a construção do projeto profissional, mas que convertem em relação ao quanto os antagonismos que os unem no projeto específico estão ligados à coerência teológica.

${ }^{14}$ Quando se planeja a prática e formação do Serviço Social da Colômbia, devem considerar as contradições sóciohistóricas que dão lugar ao seu surgimento, mas de uma forma geral, deve ser lembrado o processo histórico em que se instala na sociedade com as suas práticas sociais, suas normas legais e costumes, além das condições econômicas que determinam as relações sociais, já que cada país tem as suas contribuições particulares.
} 
formação profissional do assistente social são, respectivamente, o conjunto CFESS/CRESS (conforme Lei de Regulamentação da Profissão, Lei 8662/93) e a ABEPSS - Associação Brasileira de ensino e Pesquisa, responsável pela elaboração das Diretrizes Curriculares para os cursos de Serviço Social.

Neste sentido, essas contribuições para a intervenção podem desprender-se de compreender que a consolidação do sindicato profissional sobre constituir os mínimos comuns com relação à formação e à intervenção profissional devem ser abordados por um número representativo de profissionais e estudantes que compartilham e se comprometam em um processo de fundamentação teórico-metodológica sistemática, para identificar qual é a ação pertinente do profissional no contexto específico do capitalismo.

Para isso, é necessário um conhecimento e compreensão da realidade social mediante abordagens rigorosas do capitalismo e das relações que se estabelecem com os demais âmbitos da realidade na sociedade burguesa; evidenciando os condicionamentos, os limites, as alternativas e os desafios que tem a prática profissional nos diferentes campos onde é demandado o profissional, obtendo aspectos sobre as condições do trabalho dos(as) Trabalhadores(as) Sociais e a sua autoimagem. Segundo lamamoto (2003, p. 116-117),

(...) uma interpretação distinta do exercício profissional, que pode possibilitar para o coletivo profissional ampliar a transparência na leitura de seu desempenho, consiste em enfocar o trabalho profissional como participante de processos de trabalho que se organizam segundo as exigências econômicas e sociopolíticas do processo de acumulação, moldando-se em função das condições e relações sociais específicas em que se realiza, às quais não são idênticas em todos os contextos onde se desenvolve o trabalho do(a) Assistente Social.

\section{Dimensão ético-política do projeto profissional a partir da perspectiva histórico- crítica}

Não encontramos razões suficientes para pensar o tema da dimensão ético-política em relação ao projeto profissional quando se faz desarticulada do contexto onde o(a) Trabalhador(a) Social exerce seu campo de ação (Colômbia), e se isso está desligado da vontade e consciência de quem conforma o sindicato profissional (estudantes, professores, profissionais e pesquisadores).

É por isso que a carga do sentido que possuem estas palavras: "Projeto profissional ético-político" podem perder o seu verdadeiro conteúdo, aparecendo como clichês utilizados para fingir um processo que se estabelece, seja no papel, seja na consciência (conservadora 
"Questão Social”, intervenção profissional e projeto ético-político: três perspectivas para pensar as formas de...

ou progressista), dos profissionais que as promovem, mas faz parte de algo individual que não é questionado pelo coletivo profissional e, portanto, não transcende aos âmbitos de formação e ao exercício profissional.

Para isso, é necessário o esclarecimento das condições do posicionamento do Serviço Social como profissão que funda a sua influência no marco do capitalismo em sua etapa atual, onde as dimensões política e ética são fundamentos ontológicos, e frente às que se descarta a neutralidade enquanto os meios e fins em que se enquadra a ação profissional nunca são neutras.

\begin{abstract}
A premissa é que o atual quadro sócio político não se reduz a um plano de fundo para que se possa discutir o trabalho profissional. Este atravessa e confronta o cotidiano do exercício profissional do(a) Assistente Social, afetando suas condições e as relações de trabalho, e as condições de vida da população usuária dos serviços sociais (IAMAMOTO, 2003, p. 31).
\end{abstract}

Desde a perspectiva histórico-crítica, a compreensão das condições sócio-históricas é necessária para fazer uma leitura histórica das práticas sociais e profissionais que posicionam o Serviço Social nas relações antagônicas das classes sociais e frente às demandas das organizações e instituições que requerem a implementação das políticas sociais públicas ou privadas.

\begin{abstract}
Portanto, a atuação do Serviço Social é visceralmente polarizada por interesses sociais de classes contraditórias, inscritas na própria organização da sociedade e que se recriam em nossa prática profissional, as quais não podemos eliminar. Só nos resta estabelecer estratégias profissionais e políticas que fortaleçam alguns dos atores presentes nesse cenário. Assim, a prática profissional tem um caráter essencialmente político: surge das próprias relações de poder do Assistente Social, e não deriva exclusivamente da atuação individual do profissional ou de seu compromisso. Este se configura na medida em que sua atuação é polarizada por estratégias de classes orientadas para o conjunto da sociedade, dos quais se corporificam através do Estado e das organizações da sociedade civil, e se expressam nas políticas sociais públicas e privadas e nas organizações institucionais nos quais trabalhamos como Assistente Social (IAMAMOTO, 1997, p. 203-204).
\end{abstract}

Neste sentido, a dimensão política do projeto coletivo aponta a descobrir que os assuntos relevantes que devem ser levados em conta são: "a contradição capital / trabalho, as profundas crises econômicas-sociais da atualidade e as profundas dificuldades econômicas e políticas (IAMAMOTO, 1997, p. 200). E se complementa com outros elementos como: 
A ilusão das medidas governamentais hoje é patente: as dificuldades salariais, o aumento das disparidades sociais, a insolvência das instituições públicas prestadoras de serviços, a corrupção e as desmando de poder, o reforço da dependência do grande capital. Enfim, tudo isso aponta para o reforço e o aprofundamento da luta social e política da qual, como Assistentes Sociais, não podemos derrubar (IAMAMOTO, 1997, p. 201).

Como afirma Marilda lamamoto (1997), estes aspectos que podem ser pensados de forma desarticulada do interesse da profissão estão intimamente ligados com os compromissos profissionais frente a população a que dirigimos o nosso agir.

Sendo assim, o chamado se faz para ampliar as análises da realidade social ao contexto local e, por fim, as formas em que se produz a intervenção profissional. É pertinente partir da constituição de uma postura política profissional, pois as crises que afetam tanto as relações sociais, as condições laborais e de seguridade individual e social, afetam à todas as pessoas que vivem e promovem as condições que se reproduzem e degeneram na vida cotidiana.

Sendo conscientes do nosso lugar na cadeia produtiva (material ou imaterialmente, conforme o caso), como trabalhadores que somos por depender exclusivamente da força de trabalho e, mais que isso, ao ser o Serviço Social, uma profissão inscrita na divisão sociotécnica do trabalho, onde a nossa atividade se fundamenta na intervenção profissional que não está isenta de expor uma convicção política e que, pelo contrário, demanda uma postura coletiva, em que os profissionais devemos nos comprometer com um acionar ligado a estabelecer alguns parâmetros mínimos frente aos desafios que se apresentam pelas condições atuais as quais têm sido condenada a sociedade, pela barbárie e ultrajes do poder político e os demais entes que geram influências de terror mediante as formas de pacificação que determinam a atuação profissional nos cenários de prática (intervenção).

Além disso, aparece para nós como um desafio neutralizar o escalonado que está levando à falta de demanda da profissão que nos deveria expor desafios de duas vias, tanto para desenvolver os fundamentos ético-políticos como para articularmos coletivamente para a defesa e a reivindicação de nossos direitos laborais.

Neste sentido, é por meio de uma postura política coletiva (politizar a profissão) que devemos enfocar a atenção, e que:

(...) o desafio consiste em descobrir alternativas e possibilidades para o trabalho profissional no cenário atual; traçar horizontes para a formulação de propostas para 
enfrentar a questão social e que sejam solidárias com o modo de vida daqueles que as vivem não só como vítimas, mas também como sujeitos que lutam pela preservação e a conquista de sua vida, de sua humanidade. Essa discussão é parte dos caminhos perseguidos pelo trabalho profissional contemporâneo (IAMAMOTO, 2003, p. 95).

Para enfrentar os desafios mencionados, se reconhecem dois elementos que lamamoto (1997) estabelece como antecedentes do Serviço Social e que devem ser lembrados para não ocorrer neles ingenuamente que leva a erros reconhecidos do movimento de reconceituação que se fizeram tangíveis na denominada "intenção de ruptura" no Brasil. Estes elementos são o "messianismo" e o "fatalismo".

Estes dois elementos são uma grande entrada para pensar sobre o nosso papel profissional (autoimagem) e a intervenção profissional, pois é a partir deste reconhecimento, que se revelam atitudes profissionais que têm sido reproduzidas e consolidadas mediante práticas e discursos cotidianos, que se sustentam nas contradições que o profissional experimenta no exercício que desempenha.

Há uma exigência de romper com uma visão pessimista, fatalista e perversa do Serviço Social, calcada de uma visão determinista da lógica do capital, esvaziada de sua dinâmica contraditória, de seu movimento, de sua potencialidade de superação. O eixo determinante nessa análise é a ótica de poder, mas se vê asfixiado, quando não há mais nada para fazer além de denunciar ou lamentar. Nesta visão perversa temos um(a) profissional acomodado(a), que busca desenvolver de uma maneira ativista, burocratizada e rotineira, inúmeras e diversificadas tarefas que lhe são atribuídas; o limite do seu horizonte profissional é, no máximo, ser um tecnocrata, aperfeiçoar formal e burocraticamente a sua atuação cotidiana. Assim, se reforça a dimensão tutelar e paternalista do Serviço Social, tornando-se o Assistente Social um mero espelho da instituição patronal como um agente, mas que concretiza as estratégias de classe (IAMAMOTO, 1997, p. 205-206).

Frente ao fatalismo se colocam vários desafios dos diferentes cenários em que o profissional exerce a sua ação, pois nestes cenários é onde se estabelecem os maiores níveis de frustração.

A relação Estado-profissão, sociedade civil, instituições-profissões e empresaprofissão, geram condições de conflito com os interesses que reivindicam a classe burguesa. Estas formas de permeabilização das contradições sociais e econômicas são o maior obstáculo para a liberdade e emancipação humana.

Sobre o surgimento do "messianismo", sabe-se que: 
a visão "messiânica" e a-histórica do Serviço Social, separada do solo da história, de cunho voluntarista e subjetivista, ingênua sobre as possibilidades revolucionárias da profissão, muitas vezes rodeada de um discurso com propostas e intenções críticas, é marcada por uma visão mágica da transformação social, que passa a ser reduzida para uma questão de princípios. Muitas vezes esse discurso se reduz ao compromisso individual do(a) Assistente Social, como se o nosso desejo e propósitos individuais foram linearmente suficientes para alterar a dinâmica da vida social, caindo, não poucas vezes, em uma concepção basista ${ }^{15}$ da condição do exercício profissional (IAMAMOTO, 1997, p. 206).

Um projeto profissional se constitui ao unir os projetos individuais, coletivos e da sociedade, canalizando as forças para pensar o fazer profissional, superando o individualismo e consolidando um coletivo profissional que se esforça para transcender as condições que o capitalismo impõe na "modernidade" e/ou na pós-modernidade, superando os ideais do conservadorismo em uma profissão que deve superar os seus marcos históricos da perspectiva tradicional e entrar em uma visão mais ampla e conscienciosa dos âmbitos de onde provêm os seus principais limites. Isto é, o social convoca a construção coletiva de um projeto profissional que vise indivíduos, coletivos e sociedade, canalizando forças e saberes plurais mediante especificidades e singularidades, arranjos sociais diversos, em prol do acesso aos direitos, vida digna e transcendência da lógica neoliberal operante.

Nesta medida, as rupturas com as noções políticas tradicionais devem ser repensadas e superadas por outras concepções teórico-práticas transformadoras das condições préexistentes, estabelecendo mudanças substanciais na racionalidade, na perspectiva, nas práticas profissionais, e por fim, na formação.

Pretende-se entender a dimensão política e ética a partir das concepções tanto históricas como de totalidade, levando em conta as implicações da neutralidade política e a ética tomista e neotomista própria do positivismo e neopositivismo que se instalou e permaneceu na profissão desde a sua formação legal na Colômbia.

A ética, em sua dimensão teórica não é (ou, não deveria ser) uma prescrição de princípios definidos abstratamente; o seu conteúdo é a prático ético-moral dos homens. Assim, a quase ausência de sistematização ética na profissão até os anos

\footnotetext{
${ }^{15} \mathrm{Em}$ relação ao "basismo" e outros assuntos que são parte da intenção de ruptura que são superados, Lucía Barroco afirma: "As formas de incorporação do Marxismo por parte do Serviço Social somente adquirem condições de serem reavaliadas na segunda metade dos anos 70, no âmbito da crítica superadora do movimento de reconceituação. Assim, são apontados o seu "elitismo" teórico-metodológico, a sua ideologização em detrimento da compreensão teórico-metodológica, a sua remissão a manuais simplificados do Marxismo, a sua reprodução do economicismo e o determinismo histórico. Em termos políticos, questionase o "basismo", o voluntarismo, o "messianismo", o militantismo e o revolucionarismo" (BARROCO, 2004, p. 189).
} 
"Questão Social”, intervenção profissional e projeto ético-político: três perspectivas para pensar as formas de...

90, embora tenha contribuído para muitos equívocos, não impediu que a vivência prática foi se encarregando de criar um ethos, baseado nas experiências históricas de luta social pela liberdade (BARROCO, 2004, p. 86).

A proposta é de repensar a dimensão ética e política conforme o contexto sóciohistórico e político-cultural da Colômbia. Busca-se contribuir para uma transformação necessária das práticas de caridade que estão na vocação profissional, pois o Serviço Social não realiza ações desarticuladas do mundo do trabalho, aos Trabalhadores Sociais como classe trabalhadora da qual pertencemos dependemos de nossa força de trabalho para substituir e ter os meios para uma vida digna, pela luta por nossos direitos laborais como profissionais para serem feitas as mudanças de concepção nas dimensões ética e política.

\section{Considerações finais}

No marco da compreensão da intervenção no Serviço Social, sob a lente da perspectiva histórico-crítica, se encontra como elemento transversal a relação que constrói a categoria profissional sobre as formas de conceber a prática profissional.

Evidenciam-se, desde as primeiras obras, um chamado a configurar uma postura política através da concepção de trabalho dos Trabalhadores Sociais. Neste sentido, se coloca em prática o cenário do exercício profissional no cotidiano, enquanto as ações devem ser estabelecidas pelo coletivo profissional com relação às respostas sobre as demandas que derivam dos seus contratantes.

\footnotetext{
O profissional pode limitar-se a responder às exigências do empregador, confiandoIhe a sua adesão, ou lançar-se no esforço conjunto do coletivo profissional, aliado aos demais profissionais e aos setores populares, de propor e concretizar uma direção alternativa daquela proposta por os setores dominantes para a intervenção técnica. Trata-se, a partir do jogo de forças sociais presentes nas circunstâncias de seu trabalho, de reorientar a prática profissional ao serviço dos interesses e necessidades dos segmentos majoritários da população, consolidando junto a ela novas fontes de legitimidade para o Serviço Social (IAMAMOTO, 1997, p. 138).
}

Estes postulados que articulam categoricamente "questão social" com intervenção, articulado a um projeto ético-político, permite identificar o cenário na essência da prática profissional em conjunto com os fatores da instrumentalidade e funcionalidade profissional. Portanto, pela dependência a um fator externo entre a força de trabalho e as agências contratantes para exercê-lo, é que se necessita de um projeto ético-político da profissão. 
Essas três perspectivas devem esclarecer o panorama da instrumentalidade da profissão em função do projeto burguês dirigido a reproduzir as relações capitalistas e entendendo essa instrumentalidade como resposta da categoria para implementar políticas sociais com capacidade de compreensão dos interesses em direção aos quais são dirigidas as ações profissionais. Desta forma, quais são as demandas do social? Quais são as intervenções possíveis? De quais instrumentos o Serviço Social lança mão? Quais são as possibilidades da atuação profissional através de um projeto ético-político na contemporaneidade?

Esta provocação nos leva a pensar a necessidade de articular um quadro teóricometodológico, ético-político e operativo-instrumental, que desde a formação permita ao profissional uma visão crítica, histórica e concreta da realidade social contemporânea que enfrenta no seu cotidiano e que está marcada pelas demandas imediatas de seus contratantes.

Assim, a tarefa é pensar a autoimagem profissional, o conjunto de fundamentos teórico-metodológicos existentes atualmente nos planos curriculares do país, o ecletismo na profissão e os diferentes fundamentos teóricos que incidem e determinam a prática profissional e as ações interventivas surgidas das demandas no social. Por fim, as convergências e divergências entre territórios, projetos políticos e sociedade colocam em xeque as três perspectivas aqui trabalhadas. O social convoca, a todo momento, a construção coletiva de um projeto profissional que vise indivíduos, coletivos e sociedade, canalizando forças e saberes plurais mediante especificidades locais, regionais e territoriais em prol do acesso aos direitos, vida digna e transcendência da lógica neoliberal operante.

\section{Referências}

BARROCO, M. L. Ética y servicio social: fundamentos ontológicos. São Paulo, Brasil: Editora Cortez, 2004.

BORGIANNI, E.; GUERRA, Y.; MONTAÑO, C. (Orgs.). Servicio social crítico: Hacia la construcción del nuevo proyecto ético-político profesional. São Paulo, Brasil: Editora Cortez, 2003.

GUERRA, Y. La instrumentalidad del servicio social, sus determinaciones sociohistóricas y sus racionalidades. São Paulo, Brasil: Editora Cortez, 2007.

IAMAMOTO, M. V. Servicio social y división del trabajo. São Paulo, Brasil: Editora Cortez, 1997. 
. El servicio social en la contemporaneidad, trabajo y formación profesional. São Paulo, Brasil: Editora Cortez, 2003.

MÉSZÁROS, I. La crisis estructural del capital. Caracas, Venezuela: Ministerio del Poder Popular para la Comunicación y la Información, 2009.

MONTAÑO, C. La naturaleza del servicio social. São Paulo, Brasil: Editora Cortez, 2000.

. Tercer sector y cuestión social, crítica al patrón emergente de intervención social. São Paulo, Brasil: Editora Cortez, 2005.

. Um projeto para o serviço social crítico. Florianópolis, Brasil: Revista Katálysis, v 9, n² 2, p. 145-157, 2006.

NETTO, J. P. Capitalismo monopolista y servicio social. São Paulo, Brasil: Editora Cortez, 1997.

.; PARRA, G.; CARBALLEDA, A.; CORAGGIO, J. L.; Et al. Reflexiones en torno a la "cuestión social". En Nuevos escenarios y práctica profesional. Una mirada crítica desde el Trabajo Social. Buenos Aires, Argentina: Espacio editorial, p. 10-29, 2002.

In: BORGIANNI, E.; GUERRA, Y.; MONTAÑO, C. (Orgs.). La construcción del proyecto ético-político del servicio social frente a la crisis contemporánea en Servicio social crítico. São Paulo, Brasil: Editora Cortez, p. 271-296, 2003.

In: BORGIANNI, E.; GUERRA, Y.; MONTAÑO, C. (Orgs.). Cinco notas a propósito de la cuestión social en Servicio social crítico. São Paulo, Brasil: Editora Cortez, p. 55-69, 2003. 